\title{
Introduction: a forum for developing ideas and solutions to pension challenges
}

\author{
JEFFREY BROWN, STEVEN HABERMAN, \\ MOSHE MILEVSKY and MIKE ORSZAG
}

The next few decades will be a period of rapid demographic change that will present significant challenges to both public and private pension systems. In the next five decades, reasonably conservative estimates are that the proportion of the population aged over 65 in the developed world will roughly double. This shift in the age structure of the population will naturally create wide-ranging economic and political strains, particularly where pension provision relies extensively on pay-as-you-go systems that are inherently sensitive to demographic change.

In addition to stress caused by a shift in the age structure of the population, low fertility experience of many countries, particularly in continental Europe, will lead to substantial declines in the working age population in the next couple of decades. A decline in the availability of workers will pose challenges for firms who are likely to be under increasing pressure to attract and retain key workers. These pressures could lead to a growth in employer-provided pensions.

The challenges to developing countries over the next few decades are significantly different in nature but no less severe. A large number of pension reforms have taken place in the past ten years, in many cases at the urging of the World Bank. These reforms have brought about significant systemic change, which is quickly transforming the nature of pension provision in many countries at a speed far faster than that at which funded pensions developed in Anglo-American markets. In order to make sure that individuals receive adequate retirement income, detailed attention needs to be focused, for instance, on building up coverage, developing markets for annuities, improving consumer education, reducing administrative costs and improving governance.

It is within this context that we are proud to introduce The Journal of Pension Economics and Finance. The journal is the only academic outlet focusing entirely on the economics and finance of pension provision. The journal is associated with the International Pension Regulators and Supervisors (INPRS), a new network administered by the OECD incorporating member organizations in over 60 countries. The mission of INPRS is to bring together regulators and supervisors. It also aims to link with new ideas from the research community. This journal fits into the latter part of the INPRS objectives but clearly the ideas in the journal are not necessarily those 
of INPRS or its members. The topics covered by the journal are, however, clearly of crucial importance to the INPRS.

The journal structure consists of the four editors: Jeffrey Brown (Harvard University), Steve Haberman (City University), Moshe Milevsky (University of York, Canada), Mike Orszag (Watson Wyatt), the managing editor Andre Laboul (OECD), and advisory members. The advisory members will change over time and currently consist of: Zvi Bodie (Boston University), Axel Boersch-Supan (University of Mannheim), Robert Brown (University of Waterloo), Chris Daykin (The U.K. Government Actuary), Peter Diamond (MIT), Richard Disney (University of Nottingham), David Knox (PriceWaterhouseCoopers), Olivia Mitchell (University of Pennsylania), Naohiro Ogawa (Nihon University), John Piggott (University of New South Wales), John Shoven (Stanford University) and David Wise (Harvard University).

The editors determine which articles are accepted for publication. The managing editor coordinates the editorial office at the OECD as well as the process of providing feedback on topics of interest to the editors and the academic community from the policy and regulatory community. The advisory members of the editorial board will provide the same sort of feedback to the editors from the academic and professional communities.

The mission of the journal is to serve as a forum for the international debate on pension provision. We strive to become one of the most influential resources on pensions in the world. Achieving this ambitious goal will be hard - there are many forums for contributing to the debate on pensions even within economics and finance.

To achieve our mission, we will adhere to four core principles:

- Ideas. We will focus on publishing original ideas and contributions with a substantive economics and finance content. We will publish descriptive work or qualitative reviews only where it serves to fill an important gap.

- Independence and Diversity. The journal will be independent of any particular school of thinking on pension issues and will publish a diverse range of ideas.

- Fairness. The editors aim for a rapid and fair editorial process. Where articles are deemed by the editors to have a good chance of publication, they will be sent for double-blind anonymous outside review. The editors will strive to provide detailed, constructive and helpful comments.

- Focus. We will publish only articles pertinent to the economics and finance of pensions. Articles from actuarial science and other disciplines are welcome as long as there is a clear economics and finance context.

Examples of subjects along with illustrative questions, which fit within the context of the journal, include:

- Pension Finance. How should pensions be financed? How affordable are current pensions and social security arrangements?

- Benefit Design. What are the optimal structures of pension and related benefits? What are the incentive effects of different means of provision of retirement income? 
- Valuation. How should corporate and social security pension liabilities be valued?

- Risk Analysis. How much risk for individuals and corporations is there in different forms of pension plans?

- Investment. What is the optimal asset allocation for private pension funds? What are the best ways for pension funds to match assets and liabilities?

- Pensions \& Labour Markets. What are the labour market effects of different public and private pension arrangements?

- Private Pension Distribution \& Delivery. What is the most efficient way to ensure adequate, low cost distribution of private pensions?

- Regulation. What are the effects of different forms of regulation of private pension plans?

- Political Economy. How do political economy considerations affect the possibilities of pension reform?

- Taxation. What are the effects of different tax arrangements on private pensions?

- Governance. What are the best governance mechanisms for pension funds?

As is apparent, the subject area we have outlined is quite broad. It is therefore useful to provide some more specific illustrative examples of issues that would be useful to explore. By presenting these examples, we are seeking to convey some of the excitement of what a journal in this area could potentially achieve. These examples are hence illustrative rather than exclusive.

\section{Theory and estimation of asset-liability models (ALM)}

As pension funds mature, quantifying risks accurately becomes more important. Risks for pension funds are typically assessed using asset-liability modeling (ALM) studies. In such studies, the attention paid to dependencies is usually restricted to (macro-) economic risks such as inflation, interest rates, rates of return on investments and salary growth (as appropriate). Asset-liability modeling has important applications in insurance and other areas.

Given the importance of asset liability modeling, it would be useful to see more development of financial economics and econometric foundations. Asset-liability modeling developed from concepts such as duration and convexity matching and other ideas predominant in fixed income mathematics prior to subsequent developments in financial economics. Despite the rapid development of financial economics, there has been a remarkable lack of application of these concepts in the context of ALM models. Financial econometrics also can be used to estimate parameters in asset-liability studies.

More fundamentally, often only linear correlation is taken as a dependency concept for these risk factors. There is a need for the development of integrated risk management methods based on a more general measure of dependency for describing, modeling and analyzing the dependencies between the several risks affecting such pension schemes. Aggregate mortality risk also needs to be incorporated more generally in asset-liability studies. Considerations of parameter and model uncertainty need to be developed further as well. 


\section{Concepts in individual financial planning}

Pension system designs and public pension reforms should be based on an understanding of individual needs as well as how individuals will respond to incentives and redistribution in various alternative designs. Retirement needs for individuals will involve a mix of savings and insurance. It is thus important for there to be models to consider both aspects of pensions simultaneously. Models of consumption, insurance, short term and long term saving and asset allocation strategies and appropriate performance criteria can be developed so that optimal choices of these "savings and protection" strategies (and key parameters) can be investigated for a range of liability profiles for the individual.

An example of an area where deeper understanding is required is portfolio allocation during retirement. As participants near retirement, and have control over their pension, they are faced with portfolio decisions of when and if to annuitize their accumulated balance and convert to a pension. Modern portfolio theory (and the Markowitz frontier) has become a ubiquitous tool for asset allocation at the individual and institutional level. Unfortunately, this framework as it currently stands, does not accommodate immediate annuity products with their life-contingent status and mortality-dependent income flow. Indeed, we are now seeing the emergence of immediate annuity (IA) products with the same micro-ability to control asset allocation between fixed and variable products, similar to mutual funds and variable annuities in the accumulation phase. Models and tools are needed to aid individuals choosing among complex alternatives.

There are also basic issues of financial education. The increasing importance of defined contribution plans (and similarly designed individual pension products) places more emphasis on decisions at the level of the individual. As individuals are given more control and responsibility for their pensions and retirement income, they must be given the tools to understand and appreciate the implications of their decisions as they pertain to choices between risk and return. Many of the newly reformed pension plans that have moved towards an individual account system, are now in the hands of participants that do not have the experience, or perhaps in some cases the financial sophistication, patience or even interest, in making crucial decisions about asset allocation and annuitization.

\section{The labour market effects of pensions}

Pensions by design exist partly to affect labour market behaviour. Companies use private pensions to motivate their employees to work and, in some cases, to penalise employees for retiring late or leaving the firm early. Public pensions incentivize retirement at the ages at which pensions become payable.

These incentive effects are particularly important in imperfect markets, yet many of the models in which pensions policy is analysed feature perfect labour markets. There needs to be a better understanding of the labour market effects of pensions in imperfect labour markets.

A corollary problem to the focus on perfect market labour models is that the 
analysis focuses on labour supply rather than labour demand. Early retirement is analysed typically in the context of inappropriate incentives instead of the effect of negative labour demand shocks. There needs to be better theoretical and empirical analysis of the labour demand aspects of the effects of pension arrangements.

One key application of these developments is taxation. With incomplete knowledge about the incentive effects of pensions, it is difficult to set appropriate tax rates. For example, some firms find early retirement to be a particularly effective manner of cutting business costs. This issue arises because firms do not bear the external costs to the public system of extra early retirement. Because these considerations are not taken into account in taxation of pensions, there are higher costs to the state and a suboptimal economic outcome relative to the situation where firms were forced to bear the full cost burden of their actions.

\section{Developing approaches to managing risk from pension liabilities}

One of the key arguments made about the desirability of funded pensions is the effect on capital markets. Growth of pension assets which fosters the growth of institutional investors may well have real effects. At the same time, funded pensions create capital market issues in that pension liabilities remain largely unmarketable. This creates risk for employers who sponsor defined benefit pension plans and for life insurers who write pension annuities.

For example, insurance companies and pension funds that have guaranteed lifelong payoffs face longevity risk - as opposed to small sample risk - which might not be hedgeable by selling equal and opposite amounts of life insurance. Potential breakthroughs in the human genome project and the legal definition of life will have a dramatic impact on the duration of payout streams. The credit rating agencies and traditional re-insurers are taking a hard look at the exposure of various companies who have concentrated on annuity business. We must quantify, model and price these risks. Indeed, perhaps capital markets can securitize these potentially risks. The design, pricing and marketing of innovative retirement income products, has much to learn from the nascent field of financial engineering. Financial hedging has gone mainstream with the introduction of customized derivative products that tailor a derivatives payoff to the risk-preferences of the consumer. For a reasonable sum, one can purchase a retail derivative that makes a theoretical Arrow-Debreu security into a portfolio reality. The same cannot currently be said for mortality-contingent products. Although this is partially due to regulatory constraints, we foresee substantial developments in the derivatives market for mortality and health contingent claims.

Another issue preventing the development of a market in liabilities is that ownership of pension liabilities is ill-defined when there are surpluses and shortfalls.

\section{Theories of imperfect markets and valuation}

There is a move towards using market values for measuring assets and liabilities in defined benefit pension schemes. Currently, these exists nothing less than a theoretical chasm between the actuarial and financial-economic perspective on the value of 
pension liabilities. Yet, relatively little attention has been given to imperfect and incomplete market considerations and the implicit range of possible values in such an environment. This is an important area for exploration as the markets for pension liabilities are far from perfect or complete. In such markets, any pre-desired arbitrary payoff can not be achieved through investing in a portfolio of marketable securities. Instead, there is ambiguity and room for actuarial discretion, at least theoretically. Furthermore, where parameters are uncertain, traditional actuarial smoothing techniques (for example, in the treatment of asset gains or losses or market values of assets) may be optimal. There are hence broad potential applications to pensions issues from the theory of imperfect and incomplete financial markets, which has developed considerably in financial economics in the past two decades.

\section{The first issue}

To this end, we introduce our first issue, which contains the seeds of many of the ideas discussed above, and should serve as a benchmark for our mandate as a journal.

This first issue contains four articles. In the article, Controlling the cost of minimum benefit guarantees in public pension conversions, Kent Smetters of the University of Pennsylvania looks at valuation of guarantees. Public pension reforms that introduce DC plans often have minimum benefit guarantees. These guarantees can in some cases involve substantial implicit costs. Thus, solutions to control guarantee costs and risks are very important. Smetters outlines two potential approaches. The first places a guarantee on a 'standardised portfolio', using ideas from the catastrophic bond literature. The second involves state-contingent taxation.

In Social security as a financial asset: gender-specific risks and returns, Marianne Baxter of Boston University examines the effect of social security on women. Although the financial economics methodology used in the paper is applicable to other countries, the empirical analysis looks only at the USA. She finds that while there is much heterogeneity in returns, women are particularly susceptible to social security risk. A key conclusion is that women may have more to gain than men from a move to individual accounts in the USA.

How can China resolve its old age problem? is by Estelle James and focuses on Chinese social security. James looks at the issues and problems associated with China establishing individual accounts.

International pension swaps by Zvi Bodie (Boston University) and Robert Merton (Harvard Business School) examines the use of equity and interest rate swaps by pension funds. Whereas other financial institutions use swaps frequently, pension funds do not use swaps very much. Bodie and Merton point out that pension funds could benefit greatly through use of swaps to achieve international diversification. Swaps would enable pension funds with structural investment constraints to transform and internationalize their risk-return profile, while satisfying various domestic political and regulatory objective. At the same time, swaps would lower transaction costs and mitigate credit risk exposure.

We think the four papers in this journal are a good start. Excellent articles are planned for future issues and submissions are encouraged. 
Getting the journal started involved a lot of consultation and discussion. In addition to thanking members of the Editorial Board, we would also like to thank the following members of the research committee of the International Network of Pension Regulators and Supervisors: James Banks, Elsa Fornero, Edward Palmer, Flavio Rabelo, Reinhold Schnabel, Larry Thompson and Salvador Valdes-Prieto.

We also acknowledge discussions and other contributions from (among others): David Begg, David Blake, Gordon Clark, Paul Coombes, Csaba Feher, Tryggvi Herbertsson Robert Holtzmann, Sandeep Kapur, David Lindeman, Landis MacKellar, Mamta Murthi, Peter Orszag, Syl Schieber, Joe Stiglitz and Paul Thornton.

We are extremely grateful to the staff of the OECD including (in addition to the managing editor Andre Laboul) David Linderman, Nina Paklina, Cecile Vignial, Juan Yermo and Annette Yunus. We are above all particularly grateful to Cambridge University Press and in particular Helen Lancaster, Patrick McCartan and Lyn Chatterton. 